\title{
Studies on $\mathrm{Cd}_{1} \mathrm{Se}_{0.6} \mathrm{Te}_{0.4}$ Thin Films by Spectroscopic and Diffractometer Characterization
}

\author{
Cliff Orori Mosiori ${ }^{1}$, Duke Ateyh Oeba ${ }^{2}$ \\ ${ }^{1}$ Technical University of Mombasa \\ P. 0. Box 90420-80100, Mombasa, Kenya \\ ${ }^{2}$ Kenyatta University \\ P. 0. Box 43844-00100, Nairobi, Kenya
}

DOI: $10.22178 /$ pos.26-3

LCC Subject Category:

TP155-156, QC450-467, QD450-801

Received 12.07.2017

Accepted 12.09.2017

Published online

20.09.2017

Corresponding Author:

corori@tum.ac.ke

(c) 2017 The Authors.

This article is licensed

under a Creative

Commons Attribution

4.0 License

\begin{abstract}
Cadmium selenide tellurium is a compound containing cadmium, tellurium and selenium elements forming a combined solid. Hall measurements suggest that it is an $n$ type semiconductor. Related optical studies indicate that is transparent to infra-red radiation. Structural studies clearly show that it has a wurtzite, sphalerite crystalline forms. Cadmium is a toxic heavy metal, and selenium is only toxic in large amounts or doses. By this toxicity, cadmium selenide is a known to be carcinogen to humans; however, this does not stop investigating it for optoelectronic applications. Current research has narrowed down to investigating cadmium selenide when in the form of nanoparticles. Cadmium selenide finds applications has found applications in opto-electronic devices like laser diodes, biomedical imaging, nano-sensing, high-efficiency solar cells and thin-film transistors. By chemical bath deposition, $\mathrm{Cd}_{1} \mathrm{Se}_{0.6} \mathrm{Te}_{0.4}$ thin films were grown onto glass. Tellurium was gradually introduced as an impurity and its crystalline structure and optical properties were investigated by XRD and UV-VIS spectroscopy. The main $\mathrm{Cd}_{1} \mathrm{Se}_{0.6} \mathrm{Te}_{0.4} /$ glass characteristics were correlated with the conditions of growing and postgrowth treatment and it was found out that films were homogeneous films with controllable thickness onto the glass substrate and suitable for n-type "sandwich" heterostructures applications. Comparison of the intensities of equivalent reflexions provided a test for the internal consistency of the measurements. Equivalent reflexions in two specimens differed on average by $1.4 \%$ and $0.6 \%$ from the mean measured intensity, attesting to the high internal consistency of measurements from extended-face crystals. By comparison from data obtained from all samples showed their average deviation from the mean to be $0.9 \%$.
\end{abstract}

Keywords: cadmium selenide tellurium; $\mathrm{Cd}_{1} \mathrm{Se}_{0.6} \mathrm{Te}_{0.4}$ thin films; glass; chemical bath deposition.

\section{INTRODUCTION}

Cadmium selenide compounds are used as $n$-type semiconducting layer in different kinds of "sandwiched" optoelectronic heterostructures due to their very interesting properties. They have a band gap of about $1.74 \mathrm{eV}$, good dielectric constants of about 10.2 [13] and varying electrical resistivity of about $1 \Omega \mathrm{cm}$ to $10^{12} \Omega \mathrm{cm}$ [3]. Pure crystal of CdSe has its band edge in the near infrared and show clear transmittance far into the infrared region [6]. Their long wavelength limits determined by the onset of lattice absorption are about $1.5 \mathrm{~cm}^{-1}$ at $24.3 \mu \mathrm{m}$ [14] with a narrow impurity absorption centered at $18.5 \mathrm{um}$ which varies from one crystal of CdSe to another. They also show a nonlinear optical behavior with pulses tunable from 10 to $20 \mu \mathrm{m}$ [1]. Tellurium equally is a rare, silvery-white, brittle, lustrous metalloid that can burn in air with a greenishblue flame to form white tellurium dioxide $\left(\mathrm{TeO}_{2}\right)$. When its present in certain compounds, tellurium exists mostly in the oxidation state IV and VI depending of other conditions [12]. Tellurium is therefore a semiconductor that is slightly photosensitive with radioactive isotopes. It is among the lightest element to exhibit alpha decay. Therefore, when investigating it, caution must be exercised. Using the Sellmeier equations [10] and where $\lambda$ is in microns, it has refractive index varying as:

$$
n_{o}^{2}=4.1321+\frac{1.8587 \lambda^{2}}{\lambda^{2}-0.2187}+\frac{3.0461 \lambda^{2}}{\lambda^{2}-3380},
$$




$$
n_{e}^{2}=4.0829+\frac{2.0038 \lambda^{2}}{\lambda^{2}-0.2075}+\frac{3.5540 \lambda^{2}}{\lambda^{2}-3629},
$$

where symbols have their conventional meanings.

Different techniques could be used to grow impure CdSe thin films preparation such as chemical bath deposition [2], sputtering [9], chemical vapour deposition [8] or electrodeposition [4]. Among them, chemical bath deposition (CBD) is a simple and low-cost method and produces uniform, adherent and reproducible films. Moreover, CBD is a low temperature technique and can be used for CdSe deposition onto a wide range of substrates. Thin films of were grown by chemical bath deposition on glass using the multilayer technique is not new $[6,3]$. Pure cadmium selenide films properties are extremely sensitive to preparation conditions $[7,14]$ and therefore the aim of this work is to study the influence of tellurium impurity on structural and optical properties.

\section{METHODOLOGY}

\section{Materials and Reagents}

Cadmium acetate, $\mathrm{NH}_{3}$ aqueous solution, acetone, ethanol, sodium citrate and distilled water were purchased and used without purification. Chemical were bought from Sigma Aldrich while the glass pieces were purchased from Optical Filters Ltd.

\section{Preliminary Procedures}

Prior the deposition, the coated glass $(50 \mathrm{~mm} \times$ $25 \mathrm{~mm} \times 1 \mathrm{~mm}$ ) were ultrasonically cleaned with acetone/ethanol mixture and dried.

\section{Procedure}

Single-layer Growth. $\mathrm{Cd}_{1} \mathrm{Se}_{0.6} \mathrm{Te}_{0.4}$ / glass thin film structures were grown successively from renewed chemical bath (CB) using a precursor solution prepared from cadmium acetate, $\mathrm{NH}_{3}$ aqueous solution, sodium citrate and distilled water. The glass substrates were immersed vertically suspending them around the stirrer and the bath stirred was continuously while maintained at $70{ }^{\circ} \mathrm{C}$. After attaining thermal equilibrium, Te impurities were introduced under stirring conditions.

Multi-layer Growth. To grow a multi-layer procedure, wet glass were immersed into the hot chemical bath and only taken out after $1.0 \mathrm{hr}$, washed and re-introduced into a renewed hot chemical bath solution repeatedly. All other growth conditions were maintained.

Deposition parameters. For the two procedures in above, the deposition parameters were maintained as follows:

$$
\begin{aligned}
& {\left[\mathrm{Cd}^{2+}\right]=3 \times 10^{-3} \mathrm{M} ;\left[\mathrm{C}_{6} \mathrm{H}_{5} \mathrm{O}_{7}^{3-}\right]=1.2 \times 10^{-1} \mathrm{M} ;} \\
& {\left[\mathrm{NH}_{3}\right]=3 \times 10^{-1} \mathrm{M} ;[\mathrm{Se}]=3.1 \times 10^{-2} \mathrm{M} ;} \\
& \mathrm{pH}=10.5 ;[\mathrm{Te}]=1.85 \times 10^{-2} \mathrm{M} .
\end{aligned}
$$

All samples were washed, dried and annealed in air; at $350{ }^{\circ} \mathrm{C}$ to result into $\mathrm{Cd}_{1} \mathrm{Se}_{0.6} \mathrm{Te}_{0.4}$ thin films.

Characterization. The films were characterised by thickness using a profilometer and microweighing method and the film thickness was evaluated by averaging the resulting measurements, crystalline structure using diffractometer and obtained UV-Vis transmittance spectra from a photo Spectrometer.

\section{RESULTS AND DISCUSSIONS}

This work specifically investigated the structure and optical transmittance in the range of 300$900 \mathrm{~nm}$ wavelength which is in the UV-Vis spectroscopy (Figure 1 and Figure 2).

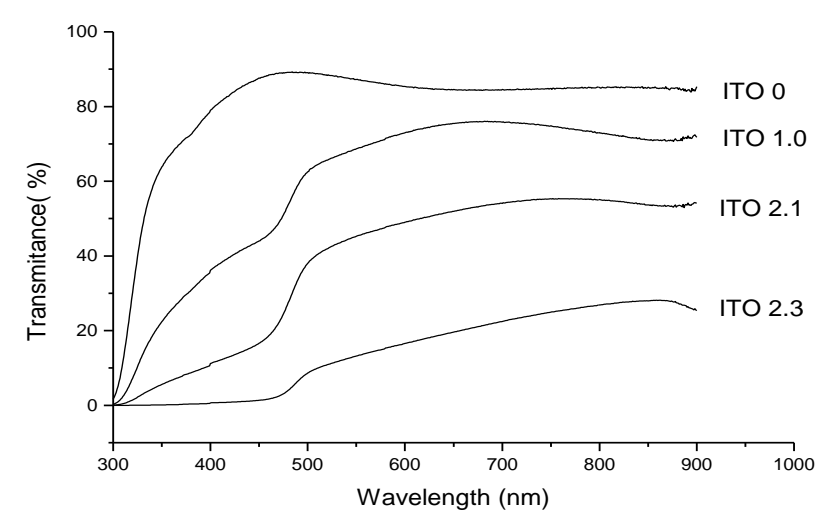

Figure 1 - Transmittance in multilayered $\mathrm{Cd}_{1} \mathrm{Se}_{0.6} \mathrm{Te}_{0.4} /$ glass film

Observed intensities were analyzed by crystallographic least-squares program and modified to include dispersion corrections and to calculate the values of the atomic scattering factors at the appropriate value of $\sin (\theta / 2)$ using the polynomial expansion [4]. 


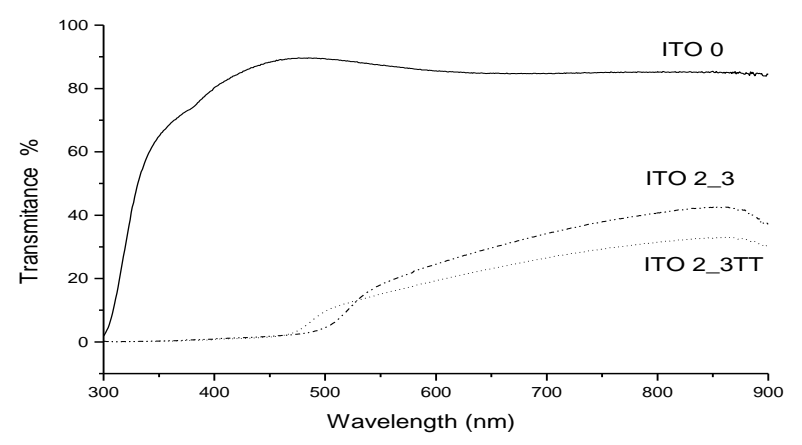

Figure 2 - Transmittance in $\mathrm{Cd}_{1} \mathrm{Se}_{0.6} \mathrm{Te}_{0.4} /$ glass after the thermal treatment

For a structure consisting of light atoms and including low-angle data the effect of replacing the usual interpolation procedure by the polynomial expansion could well be more significant.

\section{Chemical Reactions}

$\mathrm{Cd}_{1} \mathrm{Se}_{0.6} \mathrm{Te}_{0.4} /$ glass samples were grown by chemical bath deposition method from cadmium acetate solutions. The chemical bath deposition of films involves the decomposition of alkaline solutions in the presence of a metal salt in the presences of chelating agents such as ammonia or sodium citrate, whose role is to control the $\mathrm{Cd}_{1} \mathrm{Se}_{0.6} \mathrm{Te}_{0.4}$ /glass film-growing rate as follows [8]:

$$
\begin{aligned}
& \mathrm{Cd}\left(\mathrm{CH}_{3} \mathrm{COO}\right)_{2}+\mathrm{Se}^{+2}+2 \mathrm{OH}^{-} \rightarrow \\
& \rightarrow \mathrm{CdSe}+\mathrm{H}_{2} \mathrm{CN}_{2}+2 \mathrm{H}_{2} \mathrm{O}+2 \mathrm{CH}_{3} \mathrm{COO}^{-}
\end{aligned}
$$

\section{Film Thickness}

Chemical Bath technique was adapted for multilayer $\mathrm{Cd}_{1} \mathrm{Se}_{0.6} \mathrm{Te}_{0.4} /$ glass and samples with 1,2 and 4 consecutively deposited were prepared and characterised. Composition of the as prepared heterostructures, packing density, growing rate and thickness of $\mathrm{Cd}_{1} \mathrm{Se}_{0.6} \mathrm{Te}_{0.4}$ films are presented in Table 1.

\begin{tabular}{|c|c|c|c|c|c|c|}
\hline $\begin{array}{l}\text { Samples } \\
\text { code }\end{array}$ & $\begin{array}{c}\text { Heterostructures } \\
\text { Type }\end{array}$ & $\begin{array}{l}\mathrm{Cd}_{1} \mathrm{Se}_{0.6} \mathrm{Te}_{0.4} \\
\text { film type }\end{array}$ & $\begin{array}{l}\text { Total } \\
\text { dep. } \\
\text { time* }\end{array}$ & $\begin{array}{l}\text { Packing } \\
\text { density } \\
\left(\mathrm{mg} / \mathrm{cm}^{2}\right)\end{array}$ & $\begin{array}{l}\text { Film } \\
\text { thickness } \\
(\mathrm{nm})\end{array}$ & $\begin{array}{c}\text { Growing rate } \\
\text { (nm/min) }\end{array}$ \\
\hline ITO-0 & Glass & - & 0 & 0 & $20^{* *}$ & 0 \\
\hline ITO 1-0 & $\begin{array}{l}\mathrm{Cd}_{1} \mathrm{Se}_{0.6} \mathrm{Te}_{0.4} / \\
\text { glass }\end{array}$ & Mono-layer & $1 \mathrm{~h}$ & 0.098 & 17 & 0.2 \\
\hline ITO-2.1 & $\mathrm{Cd}_{1} \mathrm{Se}_{0.6} \mathrm{Te}_{0.4} /$ glass & \multirow{2}{*}{ Multi-layer } & $2 \mathrm{~h}$ & 0.470 & 89 & 0.7 \\
\hline ITO2.3 & $\mathrm{Cd}_{1} \mathrm{Se}_{0.6} \mathrm{Te}_{0.4} /$ glass & & $4 \mathrm{~h}$ & 1.434 & 243 & 1.3 \\
\hline
\end{tabular}

Table 1 - Raw data for heterostructures $\mathrm{Cd}_{1} \mathrm{Se}_{0.6} \mathrm{Te}_{0.4} /$ glass

Notes: $* \mathrm{n}=$ number of layers, $\mathrm{m}=$ deposition time; $* \star-$ manufacturer measurement

The increase of $\mathrm{Cd}_{1} \mathrm{Se}_{0.6} \mathrm{Te}_{0.4}$ /glass film thickness with the total deposition time could be noticed. Moreover, for the same deposition time, the multilayer film is almost 7 times thicker then the corresponding monolayer one. The use of a high number of successively deposited layers (coatings) determines the increase of the film thickness. One can note that for various heterostructures, the growing rate is different, increasing with the number of coatings.

\section{Optical Transmittance}

The transmission spectra of the heterostructures that contain multilayer $\mathrm{Cd}_{1} \mathrm{Se}_{0.6} \mathrm{Te}_{0.4}$ /glass films illustrates the decrease in film transparency parallel with increases in film thickness (Figure 1).
As opposed to post treated films, there seems to be an increase film transmittance (Figure 2). It can be noted that the glass substrate shows a high transparency on the entire visible domain.

\section{$X$-ray diffraction}

The X-ray diffraction were used to investigate the optical and structural properties of different $\mathrm{Cd}_{1} \mathrm{Se}_{0.6} \mathrm{Te}_{0.4}$ /glass hetero-structures (Figure 3 and Figure 4). The crystalline structure of thermally treated $\mathrm{Cd}_{1} \mathrm{Se}_{0.6} \mathrm{Te}_{0.4}$ /glass heterostructures was investigated by X-ray diffraction and characteristic bands of the hexagonal crystalline structure of the cadmium selenide could be noticed as depicted in Figure 3. 


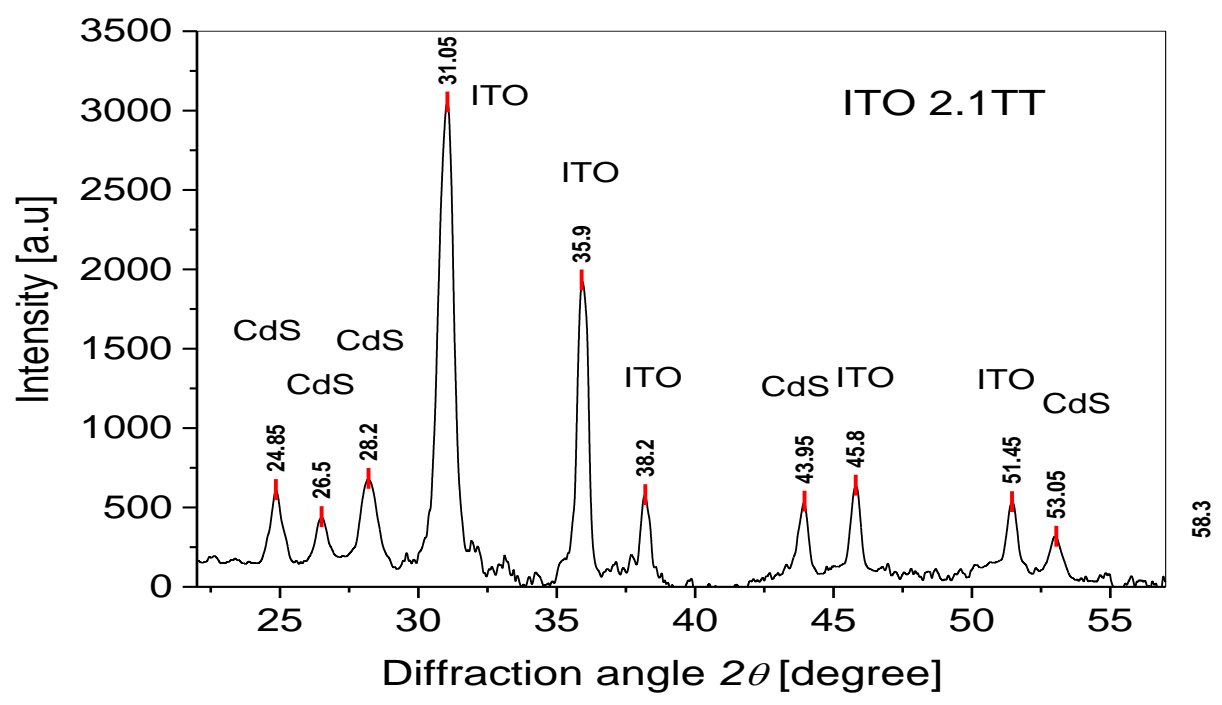

Figure 3 - XRD spectra for $\mathrm{Cd}_{1} \mathrm{Se}_{0.6} \mathrm{Te}_{0.4} /$ glass after the thermal treatment

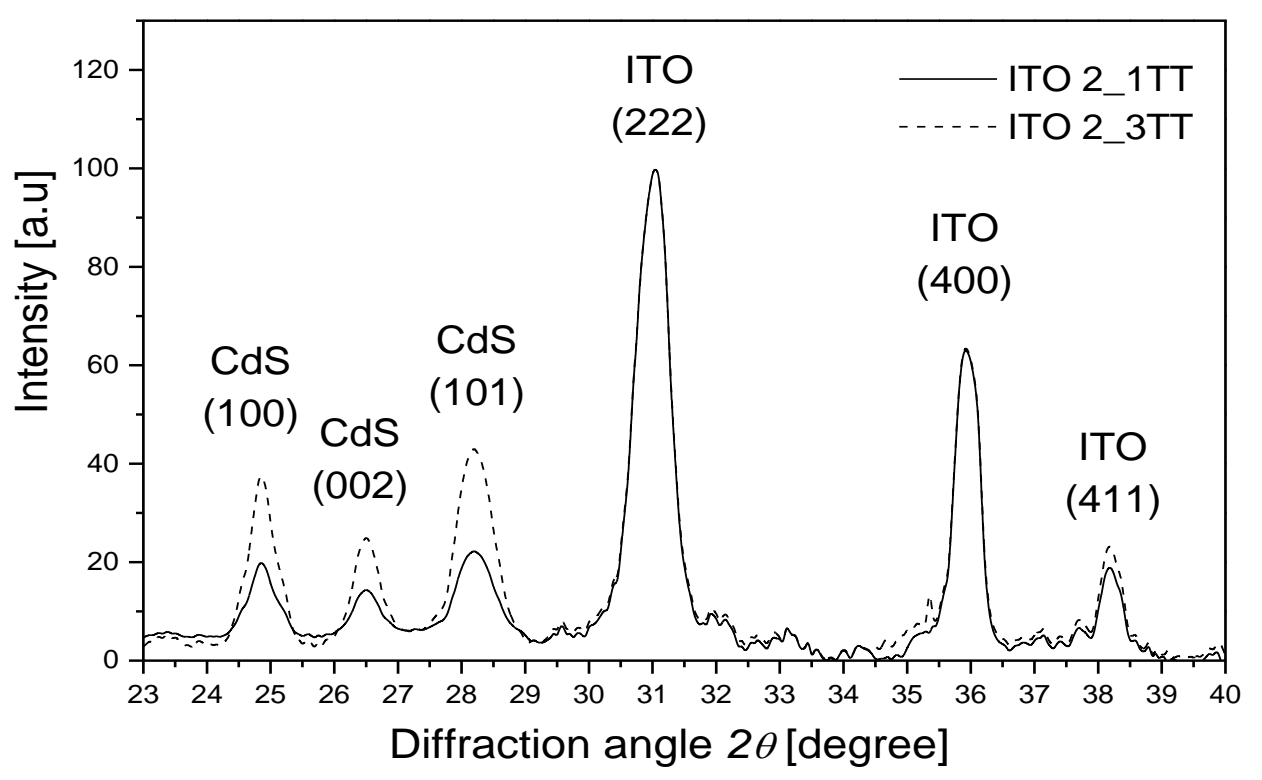

Figure 4 - XRD spectra for $\mathrm{Cd}_{1} \mathrm{Se}_{0.6} \mathrm{Te}_{0.4} /$ glass with multilayer $\mathrm{CdS}$ films

It was also noted that the crystallinity of the films were high as a result of post-growing thermal treatment. Therefore, in order to compare the effect of multiple layers on crystalline structure observed, the XRD spectra were first normalised in rapport with (222) peak of the indium-tin oxide as shown in Figure 4. The spectra normalisation was used to input in evidence of the increase of the three XRD characteristic bands observed in $\mathrm{Cd}_{1} \mathrm{Se}_{0.6} \mathrm{Te}_{0.4}$ / glass i.e. (100), (002), (101). This observation was attributed to the presence of a higher $\mathrm{Cd}_{1} \mathrm{Se}_{0.6} \mathrm{Te}_{0.4}$ crystal amount on the surface of glass.

\section{CONCLUSION}

Thin films of $\mathrm{Cd}_{1} \mathrm{Se}_{0.6} \mathrm{Te}_{0.4}$ were synthesized using special CBD. It proved to be a convenient deposition method since its films were well adhered to and were also homogeneous films with controllable thickness onto the glass substrate. Powder $\mathrm{X}$-ray analysis confirmed the fundamental diffraction patterns of $\mathrm{Cd}_{1} \mathrm{Se}_{0.6} \mathrm{Te}_{0.4}$. UV-Vis and XRD investigation illustrated the quality of the as prepared $\mathrm{Cd}_{1} \mathrm{Se}_{0.6} \mathrm{Te}_{0.4}$ hetero-structures as determined, from X-ray intensity data obtained with extended-face crystals [11]. The wurtzite parameter $u$ was found to be $0.37679 \pm 0.00012$. 
Comparison of the intensities of equivalent reflexions provided a test for the internal consistency of the measurements. Equivalent reflexions in the samples differed on average by $1.4 \%$ and $0.6 \%$ from the mean measured intensity, attesting to the high internal consistency of measurements from extended-face crystals. By comparing data obtained from all its samples their average deviation from the mean to be $0.9 \%$.

\section{ACKNOWLEDGEMENTS}

The authors acknowledge the support given by Dr. Walter Kamande Njoroge of Kenyatta University in performing the XRD spectra and Mr Maera John of Maasai Mara University for performing transmittance measurements.

\section{REFERENCES}

1. Chen, J., Gao, Y., Xu, Z., Wu, G., Chen, Y., \& Zhu, C. (2006). A novel fluorescent array for mercury (II) ion in aqueous solution with functionalized cadmium selenide nanoclusters. Analytica chimica acta, 577(1), 77-84. doi: 10.1016/j.aca.2006.06.039

2. García-Santamaría, F., Brovelli, S., Viswanatha, R., Hollingsworth, J. A., Htoon, H., Crooker, S. A., \& Klimov, V. I. (2011). Breakdown of volume scaling in Auger recombination in CdSe/CdS heteronanocrystals: the role of the core- shell interface. Nano letters, 11(2), 687-693. doi: 10.1021/nl103801e

3. Hossain, M. A., Jennings, J. R., Koh, Z. Y., \& Wang, Q. (2011). Carrier generation and collection in $\mathrm{CdS} / \mathrm{CdSe}$-sensitized $\mathrm{SnO}_{2}$ solar cells exhibiting unprecedented photocurrent densities. Acs Nano, 5(4), 3172-3181. doi: 10.1021/nn200315b

4. Ithurria, S., Bousquet, G., \& Dubertret, B. (2011). Continuous transition from 3D to 1D confinement observed during the formation of CdSe nanoplatelets. Journal of the American Chemical Society, 133(9), 3070-3077. doi: 10.1021/ja110046d

5. Lee, J. S., Kovalenko, M. V., Huang, J., Chung, D. S., \& Talapin, D. V. (2011). Band-like transport, high electron mobility and high photoconductivity in all-inorganic nanocrystal arrays. Nature nanotechnology, 6(6), 348-352. doi: 10.1038/nnano.2011.46

6. Liu, Y. H., Wang, F., Wang, Y., Gibbons, P. C., \& Buhro, W. E. (2011). Lamellar assembly of cadmium selenide nanoclusters into quantum belts. Journal of the American Chemical Society, 133(42), 17005-17013. doi: 10.1021/ja206776g

7. Owen, J. S., Park, J., Trudeau, P. E., \& Alivisatos, A. P. (2008). Reaction chemistry and ligand exchange at cadmium- selenide nanocrystal surfaces. Journal of the American Chemical Society, 130(37), 12279-12281. doi: 10.1021/ja804414f

8. Pernik, D. R., Tvrdy, K., Radich, J. G., \& Kamat, P. V. (2011). Tracking the adsorption and electron injection rates of $\mathrm{CdSe}$ quantum dots on $\mathrm{TiO}_{2}$ : linked versus direct attachment. The Journal of Physical Chemistry C, 115(27), 13511-13519. doi: 10.1021/jp203055d

9. Pradhan, N., Goorskey, D., Thessing, J., \& Peng, X. (2005). An alternative of CdSe nanocrystal emitters: pure and tunable impurity emissions in ZnSe nanocrystals. Journal of the American Chemical Society, 127(50), 17586-17587. doi: 10.1021/ja055557z

10. Qian, L., Zheng, Y., Xue, J., \& Holloway, P. H. (2011). Stable and efficient quantum-dot light-emitting diodes based on solution-processed multilayer structures. Nature photonics, 5(9), 543-548. doi: 10.1038/nphoton.2011.171

11. Robel, I., Subramanian, V., Kuno, M., \& Kamat, P. V. (2006). Quantum dot solar cells. Harvesting light energy with $\mathrm{CdSe}$ nanocrystals molecularly linked to mesoscopic $\mathrm{TiO}_{2}$ films. Journal of the American Chemical Society, 128(7), 2385-2393. doi: 10.1021/ja056494n

12. Skaff, H., Ilker, M. F., Coughlin, E. B., \& Emrick, T. (2002). Preparation of cadmium selenidePolyolefin composites from functional phosphine oxides and ruthenium-based metathesis. Journal of the American Chemical Society, 124(20), 5729-5733. doi: 10.1021/ja012576+ 
13. Werlin, R., Priester, J. H., Mielke, R. E., Krämer, S., Jackson, S., Stoimenov, P. K., ... \& Holden, P. A. (2011). Biomagnification of cadmium selenide quantum dots in a simple experimental microbial food chain. Nature nanotechnology, 6(1), 65-71. doi: 10.1038/nnano.2010.251

14. Yu, W. W., Qu, L., Guo, W., \& Peng, X. (2003). Experimental determination of the extinction coefficient of CdTe, CdSe, and CdS nanocrystals. Chemistry of Materials, 15(14), 2854-2860. doi: $10.1021 / \mathrm{cm} 034081 \mathrm{k}$ 